\title{
Genetic deletion of dectin-1 does not affect the course of murine experimental colitis
}

\author{
Sigrid EM Heinsbroek ${ }^{1,5^{*}}$, Anneke Oei ${ }^{2}$, Joris JTH Roelofs ${ }^{3}$, Shobhit Dhawan ${ }^{1}$, Anje te Velde ${ }^{1}$, Siamon Gordon ${ }^{4}$ and
} Wouter J de Jonge ${ }^{1}$

\begin{abstract}
Background: It is believed that inflammatory bowel diseases (IBD) result from an imbalance in the intestinal immune response towards the luminal microbiome. Dectin-1 is a widely expressed pattern recognition receptor that recognizes fungi and upon recognition it mediates cytokine responses and skewing of the adaptive immune system. Hence, dectin-1 may be involved in the pathogenesis of IBD.

Methods: We assessed the responses of dectin-1 deficient macrophages to the intestinal microbiota and determined the course of acute DSS and chronic Helicobacter hepaticus induced colitis in dectin-1 deficient mice.

Results: We show that the mouse intestinal microbiota contains fungi and the cytokine responses towards this microbiota were significantly reduced in dectin-1 deficient macrophages. However, in two different colitis models no significant differences in the course of inflammation were found in dectin-1 deficient mice compared to wild type mice.

Conclusions: Together our data suggest that, although at the immune cell level there is a difference in response towards the intestinal flora in dectin-1 deficient macrophages, during intestinal inflammation this response seems to be redundant since dectin-1 deficiency in mice does not affect intestinal inflammation in experimental colitis.
\end{abstract}

Keywords: Dectin-1, Macrophages, Colitis, Innate immunity, Fungi, Intestine

\section{Background}

Pattern recognition receptors (PRR) are important for host recognition of microorganisms. Various groups of PRR are known which include the Toll-like receptors (TLR), NOD-like receptors and C-type lectin-like receptors (CLR). From many studies investigating TLR and NLR receptor function in the intestine it became clear that interaction between the intestinal microbiome and PRRs expressed in the intestine is important in modifying the intestinal immune system. TLRs and NLRs have been shown to be involved in regulating epithelial barrier function, secretion of antimicrobial peptides, IgA production and secretion into the intestinal lumen, lymphoid tissue development and $\mathrm{T}$ cell function $[1,2]$. Furthermore, Myd88, several TLRs, NOD2 and NLPR3 deficient mice have all been shown to be more

\footnotetext{
* Correspondence: s.e.heinsbroek@amc.uva.nl

${ }^{1}$ Tytgat Institute for Liver and Intestinal Research, Academic Medical Center, University of Amsterdam, AMC, Amsterdam, The Netherlands Full list of author information is available at the end of the article
}

susceptible to Dextran Sulphate Sodium (DSS) induced colitis [3-9]. From patient studies it is clear that various mutations in PRR are associated with IBD [10-13].

The current research on the host interactions with the microbiota mainly focuses on the bacterial component, however fungi are also present in the intestine [14], and interact with pattern recognition receptors, mainly CLRs like dectin-1, mannose receptor and DC-SIGN [15]. More than 55\% of Crohn's Disease (CD) patients make antibodies against the mannan component of fungi compared to only $8 \%$ of healthy individuals and antibody titre is thought to be related to disease severity [16]. CD patients also make antibodies against other fungal components such as chitin and $\beta$-glucans $[16,17]$. Therefore fungi and the PRR recognising them may play a role in intestinal homeostasis.

CLRs are expressed in the intestine however, the interaction between CLRs and the intestinal microbiota is not well studied and in this paper we focus on dectin1 . Dectin- 1 binds $\beta$-glucans found on fungi and upon
C Biomed Central 
recognition mediates phagocytosis and various cytokine responses including TNF- $\alpha$ and IL-10 production [18-21]. Co-stimulation of dectin-1 and TLR2-TLR6 has been shown to increase stimulation for TNF $\alpha$, IL-12 and IL-2 production [19,20,22]. Dectin-1 has also been shown to induce dendritic cell maturation and direct $\mathrm{T}$ cell Th17 responses directly linking innate and adaptive immunity $[23,24]$. However, little is known about the role of dectin-1 in maintaining intestinal homeostasis. Dectin-1 is highly expressed in the intestine [25] and humans with $C D$ have also been shown to have increased numbers of dectin-1 expressing inflammatory cells in the intestine compared with healthy individuals [26]. Together this implies that dectin-1 may play a role in intestinal immunity.

In order to establish the role of dectin- 1 in intestinal immunity we determined dectin-1 expression in mouse colon and investigated responses towards the intestinal microbiota by macrophages deficient in dectin-1. Furthermore, we induced colitis in dectin-1 deficient mice using DSS colitis and a Helicobacter hepaticus induced colitis model to investigate the role of dectin-1 in intestinal inflammation.

\section{Methods}

\section{Animals}

Breeding colonies of C57BL/ 6 and C57BL/6 dectin- $1^{-/-}$ (A kind gift from Gordon D. Brown) mice were housed and maintained under specific pathogen free conditions in our animal facility at the Academic Medical Center in Amsterdam. Animals were kept and handled in accordance with the guidelines of the Animal Research Ethics Committee of the University of Amsterdam.

\section{Determination of fungi}

1 gram of mouse faeces was dissolved in PBS and plated on Sabouraud agar plates containing penicillin and gentamicin. The colonies were identified using an Auxacolor identification kit (Bio-rad).

\section{Colitis experiments}

Animals were sex-matched and between 8 and 12 weeks of age at the time of study. For DSS colitis experiments 1,5\% (w/v) DSS (TdB Consultancy, Uppsala, Sweden) was added to the drinking water for 7 days. Body weight was recorded daily, and weight loss on day 7 as compared with day 0 was calculated. On day 7 of DSS administration, animals were killed and organs collected. The wet weight of spleen and colon was recorded together with the total length of the colon. Colon weight per $5 \mathrm{~cm}$ was used as a disease parameter.

For Helicobacter hepaticus induced colitis $H$. hepaticus NCI-Frederick isolate 1A (strain 51449; American Type Culture Collection) was grown and maintained as previously described [27]. Mice were inoculated intragastrically on days 0,2 , and 4 with $5 \times 10^{7}-2 \times 10^{8} \mathrm{CFU}$ $H$. hepaticus. Anti-IL-10R monoclonal antibody was produced and characterized as previously described [28]. Antibody treatment was commenced on the day of the first inoculation with $H$. hepaticus, and mice received weekly i.p. injections of $1 \mathrm{mg}$ anti-IL-10R for the duration of the experiment. After 4 weeks animals were killed and blood, spleen, liver, cecum and colon collected.

\section{Histochemistry}

The longitudinally divided colons were rolled, fixed in $4 \%$ formalin and embedded in paraffin for routine histology. An experienced pathologist evaluated formalinfixed haematoxylin tissue sections microscopically, in a blinded fashion. Colons were evaluated, and graded from 0 to 4 as an indication of incidence and severity of inflammatory lesions based on the extent of the area involved, the number of follicle aggregates, oedema, fibrosis, hyperplasia, erosion/ulceration, crypt loss and infiltration of granulocytes and mononuclear cells as indicated in Table 1. The total inflammation score was calculated as the average score of the above.

\section{Immunohistochemistry}

Frozen sections of mouse colon $(10 \mu \mathrm{m})$ were processed for immunohistochemistry as previously described [25]. Briefly, slides were ethanol fixed and blocked in $10 \%$ normal rabbit serum for $10 \mathrm{~min}$. The slides were drained and incubated with purified mAb $2 \mathrm{~A} 11$ or the rat isotype control at $10 \mu \mathrm{g} / \mathrm{ml}$ for $2 \mathrm{~h}$. Endogenous peroxidase was quenched using $0.3 \% \mathrm{H}_{2} \mathrm{O}_{2}$ (Sigma-Aldrich Co. Ltd., St. Louis, MO) in 0,5\% normal rabbit serum. After washing in PBS, sections were incubated with biotinylated mouse-adsorbed rabbit anti-rat IgG for $30 \mathrm{~min}$. After washing, slides were treated with the avidin-biotin-complex (ABC)-horseradish peroxidase (HRP) reagent for $30 \mathrm{~min}$. followed by HRP substrate NovaRed treatment. Slides were counterstained with haematoxylin (Vector Laboratories), dehydrated with alcohol, cleared with xylene, and mounted with microscopy Entellan (Merck).

\section{Fluorescent immunohistochemistry}

Slides were acetone fixed and blocked in 10\% normal rabbit serum for $15 \mathrm{~min}$. Slides were drained and incubated with purified mAb $2 \mathrm{~A} 11$ or the rat isotype control at $10 \mu \mathrm{g} / \mathrm{ml}$ for 1 hour. After washing in PBS, sections were incubated with Alexa 568 labelled goat anti rat IgG (Molecular probes) for 1 hour. After washing sections were incubated with FITC conjugated anti-mouse CD11b for 1 hour. Slides where washed and mounted in mounting medium containing DAPI (Vectashield). 
Table 1 Colitis total inflammation score

\begin{tabular}{llllll}
\hline score & $\mathbf{0}$ & $\mathbf{1}$ & $\mathbf{2}$ & $\mathbf{3}$ & $\mathbf{4}$ \\
\hline Area involved & $0 \%$ & $1-10 \%$ & $10-25 \%$ & $25-50 \%$ & $>50 \%$ \\
follicles & Normal (0-1) & Minimal (2-3) & Mild (4-5) & Moderate (6-7) & Severe $(>7)$ \\
edema & Absent & Minimal & Mild & Moderate & Severe \\
fibrosis & Absent & Minimal & Mild & Moderate & Severe \\
Erosion/ulceration & $0 \%$ & $1-10 \%$ & $10-25 \%$ & $25-50 \%$ & $>50 \%$ \\
Crypt loss & $0 \%$ & $1-10 \%$ & $10-25 \%$ & $25-50 \%$ & $>50 \%$ \\
granulocytes & Normal & Minimal increase & Mild increase & Moderate increase & Severe increase \\
Mononucl. cells & Normal & Minimal increase & Mild increase & Moderate increase & Severe increase \\
\hline
\end{tabular}

The total inflammation score was determined by the average score of the following criteria: area involved, the number of follicle aggregates, oedema, fibrosis, hyperplasia, erosion/ulceration, crypt loss and infiltration of granulocytes and mononuclear cells.

\section{Measurements of colonic cytokines}

Frozen colonic tissue was homogenized on ice in Greenberger Lysis Buffer (150 mM NaCl, $15 \mathrm{mM}$ Tris, $1 \mathrm{mM}$ $\mathrm{MgCl} \cdot 6 \mathrm{H}_{2} \mathrm{O}, 1 \mathrm{mM} \mathrm{CaCl} 2,1 \%$ Triton) with protease inhibitor cocktail from Roche (11697498001), pH 7.4, diluted 1:1 with PBS. Protein concentrations of IL-12, IFN $\gamma$, TNF $\alpha$, IL-10, MCP-1 and IL-6 were measured in homogenates by cytometric bead array multiplex assay (BD Biosciences, San Jose, CA, USA) or using ELISA kits (R\&D) according to manufacturer's protocol.

\section{Primary macrophage experiments}

Thioglycollate-elicited peritoneal macrophages were isolated 4 days after intraperitoneal injection of $1 \mathrm{ml} 4 \%$ (w/ v) Brewer's thioglycollate medium (BD). $2.5 \times 10^{5}$ primary macrophages were plated in 24 well tissue culture plates with RPMI (Invitrogen) containing $50 \mathrm{IU} / \mathrm{ml}$ Penicillin, $50 \mu \mathrm{l} / \mathrm{ml}$ streptomycin and $2 \mathrm{mM} \mathrm{L}$-glutamine at $37^{\circ} \mathrm{C}$ in $5 \% \mathrm{CO}_{2}$. After 2 hours, non-adherent cells were removed by washing three times with medium. Diluted cecum content, LPS or zymosan (Molecular Probes) were added and incubated with the cells for 24 hours. Diluted cecum content was produced by suspending the contents of a mouse cecum in $50 \mathrm{ml}$ PBS which was subsequently filtered over a 40 um filter and frozen at $-20^{\circ} \mathrm{C}$ and used in a 1:1000 dilution. After 24 hours incubation no growth of micro-organisms was found in the wells and no cell death was observed by microscopic check for floating cells. Cytokine levels were determined using ELISA kits (R\&D) according to manufacturer's protocol.

\section{Statistical analysis}

All data are expressed as mean \pm s.d. The statistical significance of the differences was evaluated using an unpaired $t$ test. Statistical significance was defined as $P<0.05$.

\section{Results}

\section{Dectin-1 localisation in mouse intestine}

We started our investigation by confirming that dectin-1 is located in the large intestine of mice.
Immunohistochemical staining showed that dectin-1 is expressed in the lamina propria of the mouse colon (Figure 1A). As expected dectin-1 deficient mice did not show staining for dectin-1 in the intestine (data not shown). During DSS induced colitis the number of dectin-1 expressing cells in WT animals increased dramatically, suggesting an interaction with the intestinal microbiota under inflammatory conditions (Figure 1A). Fluorescent double staining showed that the main cells expressing dectin-1 in the intestine where also positive for CD11b i.e. macrophages, dendritic cells and neutrophils (Figure 1B).

\section{Dectin-1 mediated cytokine responses towards intestinal microbiota}

To determine if dectin-1 is able to respond towards fungal or food components in mouse faeces we used WT thioglycollate-elicited peritoneal macrophages which are known to express dectin-1 [29] and compared their cytokine responses with those isolated from dectin-1 deficient mice (Figure 1C and 1D). As a positive control we incubated these cells with zymosan (a $\beta$-glucan containing particle and known ligand for dectin-1). Dectin-1 deficient macrophages showed a $50 \%$ reduction in both TNF $\alpha$ and IL-10 response after 24 hour incubation with zymosan. We also incubated macrophages with bacterial components like LPS, LTA and MDP which are not thought to interact with dectin- 1 and indeed there were no differences in TNF $\alpha$ and IL-10 responses between WT and dectin-1 deficient macrophages (Figure 1C and 1D) showing that dectin-1 deficient macrophages were selectively deficient in dectin-1 specific responses and developed normally. Diluted mouse faeces induced IL-10 (Figure 1C) and TNF $\alpha$ (Figure 1D) production in WT macrophages. Faeces contains a whole array of various stimuli and our mouse faeces seems to contain components that can induce a high IL-10 response but does not stimulate TNF $\alpha$ production as much as zymosan or LPS do. 


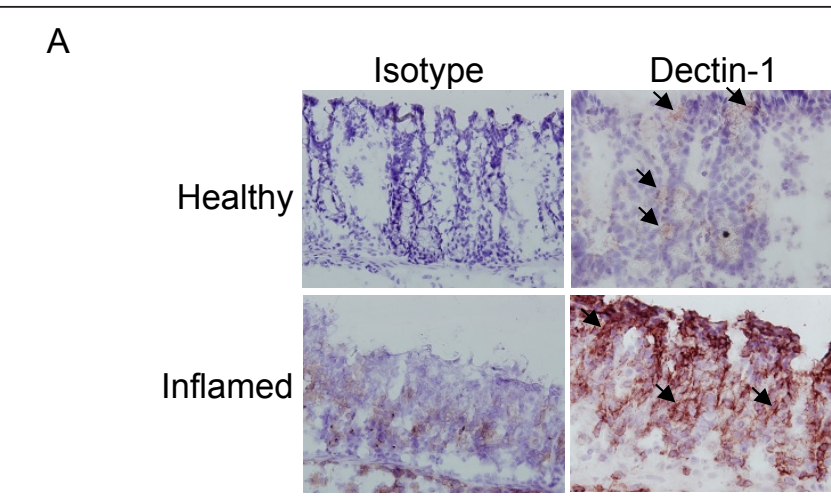

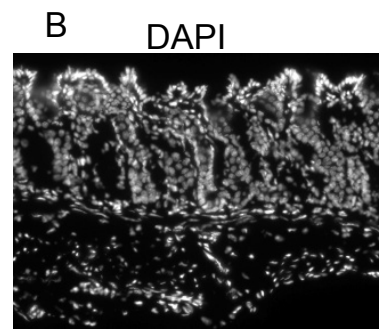

DAPI
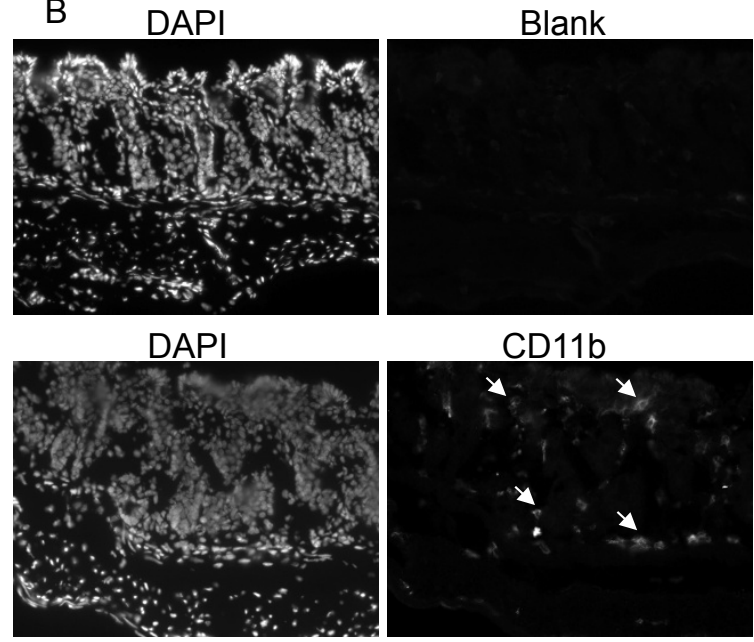

CD11b
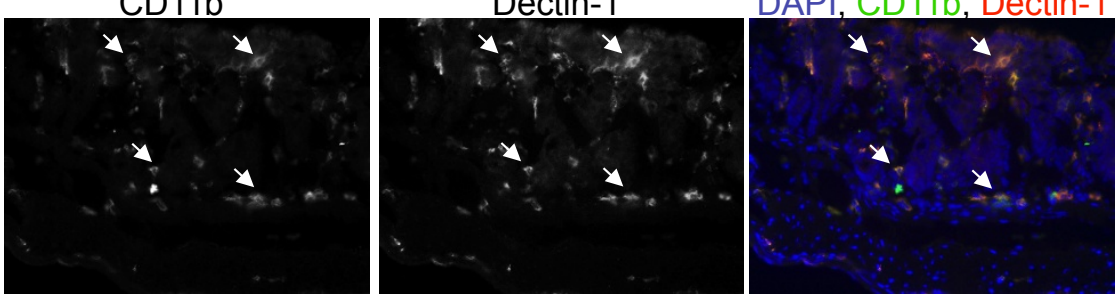

C

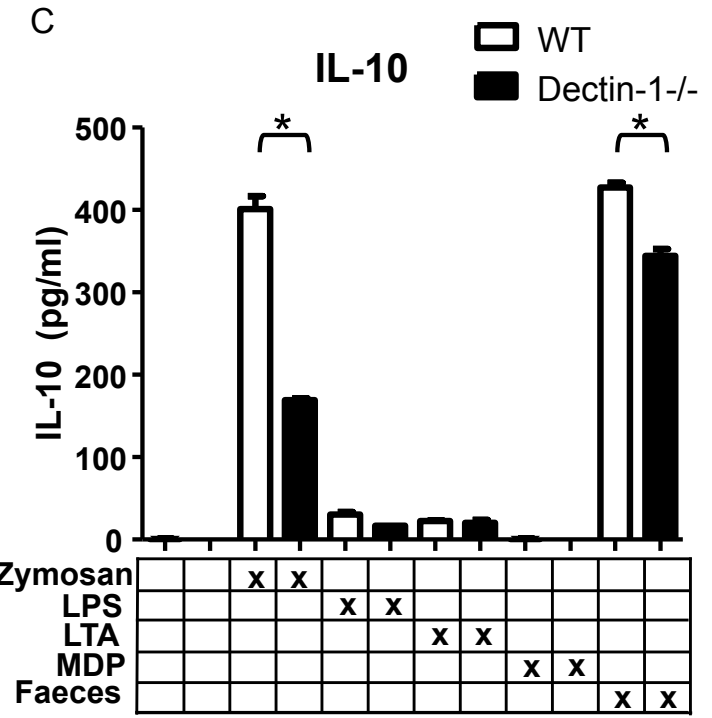

D

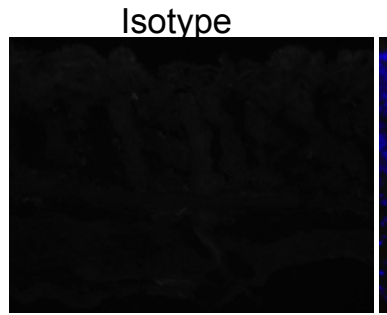

DAPI, Blank, Isotype

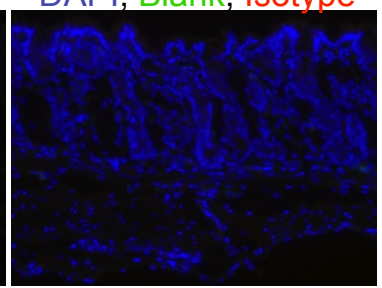

DAPI, CD11b, Dectin-1

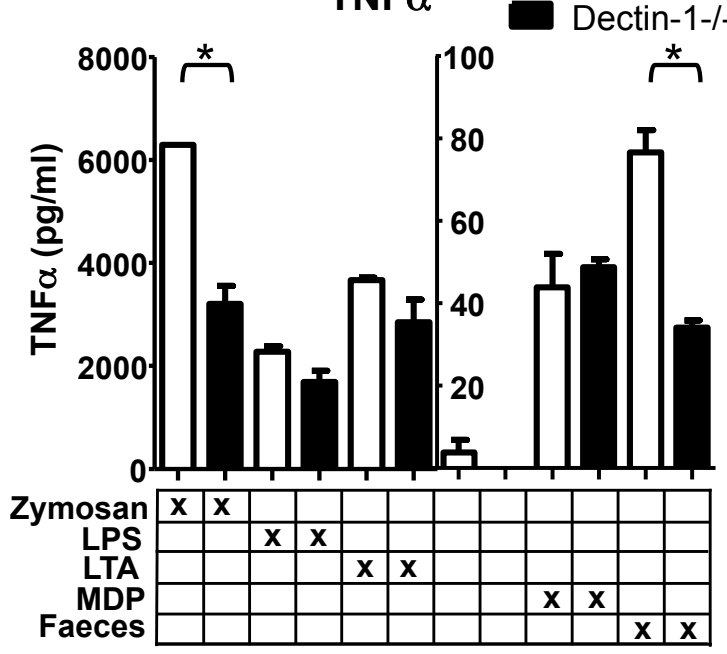

Figure 1 Dectin-1 expression in colon and its involvement in macrophages activation after incubation with mouse faeces. A) Dectin-1 staining (Nova Red) of WT colon using 2A11 on frozen sections. Sections were counterstained with haematoxylin. Representative image of uninflamed tissue shows some dectin-1 expressing cells (arrows) in the mucosa. Representative image of inflamed colon after 7 days of DSS induce colitis showing an increase in dectin-1 expressing cells. The antibodies seemed to stick more to the inflamed tissue as is shown with the isotype control staining. B) Fluorescent immunohistochemistry showing DAPI, CD11b and dectin-1 staining of healthy intestine showing that dectin-1 expressing cells also express CD11b suggesting its macrophages, dendritic cells and neutrophils in the intestine that express dectin-1 (arrows). TNF $\alpha$ (C) and IL-10 (D) protein concentrations were measured in the supernatants of thioglycollate elicited macrophages isolated from WT C57BL/6 (white bars) or C57BL/6 dectin-1-/- (black bars) mice. Macrophages were incubated for 24 hours at $37^{\circ} \mathrm{C}$ with medium, zyomsan $(0.5$ particles/cell), LPS $(100 \mathrm{ng} / \mathrm{ml})$, LTA $(5 \mathrm{ug} / \mathrm{ml})$, MDP $(10 \mathrm{ug} / \mathrm{ml})$ or supernatants of mouse faeces. These data are representative of three independent experiments done in duplicate, error bars indicate the SD. A t-test was used for statistical analysis. ${ }^{*}, p<0.05$. 
IL-10 and TNF $\alpha$ responses depend on the combination of pattern recognition receptors that are triggered. It has been shown that different bacteria are able to induce completely different cytokine profiles and can even work against each other [30,31]. The difference in magnitude of IL-10 and TNF $\alpha$ induced by faeces compared to zymosan is very likely due to different cell activation by the components, however a role for dectin-1 in the responses is clear in both stimuli since in dectin1-/- macrophages these cytokine responses were significantly reduced, suggesting that dectin-1 deficient macrophages lack a response towards the fungal or food components found in the mouse intestinal microbiota (Figure 1C and 1D). The results shown are the response towards WT faeces, the same results were found when using dectin-1-/- faeces which suggests there are no differences in the intestinal microbiota between these mice.

A yeast classified as one of the Rhodotorula species was the only fungal component cultured consistently in faeces of both dectin-1-/- and WT mice (data not shown). Rhodotorula sp. can be found in faeces [32,33] and are considered non pathogenic [34]. Rhodotorula sp. are not considered to be medically important which made it impossible for us to further determine the exact species on our premises. Nonetheless these data show that dectin-1 could be involved in responses towards the fungal microbiota found in mouse intestine.

\section{DSS induced colitis in dectin-1 deficient mice}

Next, we tested the effect of dectin-1 deficiency in an experimental model of DSS colitis. DSS is widely used as an inducer of inflammation in the intestine. It causes damage to the epithelial lining of the intestine which increases the interaction of the microbiota with the intestinal immune system, leading to an acute inflammation mainly involving innate immune cells [35]. Since dectin-1 is expressed in the myeloid compartment of the mouse intestine and is up-regulated during colitis (Figure 1A and 1B) and the lack of dectin-1 leads to reduced production of TNF- $\alpha$ and IL-10 production by macrophages we hypothesised that dectin-1 deficient mice would develop less inflammation after inducing DSS colitis.

To test this we induced DSS colitis and after 7 days mice lost 5-20\% weight due to disease but no significant differences were found in weight loss between dectin-1 deficient and WT mice (Figure 2A). No differences in spleen weight were found (data not shown). Colon weight, which is a measure of colon inflammation and increases due to cell infiltration and oedema, did not show significant differences between the two groups either (Figure 2B). Histological scoring showed that both WT and dectin-1 deficient mice had equal severe inflammation in the intestine with crypt loss, crypt erosion, ulceration, oedema and infiltration of both monocytes and granulocytes. No significant differences were found in these parameters in intestinal inflammation (Figure 2F). Representative pictures of healthy colon, WT inflamed colon and dectin-1-/- inflamed colon are shown in Figure 2C-D. We also analysed cytokine levels in mouse colons and serum and were able to measure TNF- $\alpha$, MCP-1 and IL-10 in the colon lysates. Colons of mice without induced inflammation did not contain measurable cytokine levels (data not shown) and no significant differences were found between the two groups in inflamed colons (Figure 2G-I). Unexpectedly, these data show that DSS colitis in dectin-1 deficient mice develops the same as in WT mice.

\section{Helicobacter hepaticus induced colitis in dectin-1 deficient mice}

Since DSS induced colitis did not show a role for dectin-1 in intestinal inflammation we tested another colitis model that is microbiota driven. $H$. hepaticus infected C56BL6 mice that received I.P injections with anti-IL-10 receptor antibodies develop a chronic typhlocolitis over the course of four weeks which is $\mathrm{T}$ cell dependent with a mixed Th1/Th17 response [27]. The mechanisms through which $H$. hepaticus is able to induce chronic typhlocolitis are still unclear [36]. Results were variable among different animals and no significant differences were found in weight, spleen weight, colon and cecum pathology (Figure 3A, B, F and 3G). Representative pictures of healthy cecum, WT inflamed cecum and dectin-1-/- inflamed cecum are shown in Figure 3C-E. Levels of inflammatory cytokines were measured in lysed colon and serum samples, only IL-10 and MCP-1 were above the detection limit in the lysed colon, but no consistent or significant differences were found between WT and dectin-1 deficient animals (Figure 3H and 3I).

\section{Discussion}

The intestinal immune system is shaped by its interaction with the microbiome and vice versa [1,37-39]. Dectin-1 is a PRR able to influence innate and adaptive immune responses upon recognition of fungi [40]. Indeed our in-vitro data show that faeces from our mice are able to induce dectin-1 dependent cytokine responses. Our data suggest that the luminal flora or food components from our mice are able to interact with dectin-1 and stimulate IL-10 and TNF- $\alpha$ production by macrophages. Importantly however, our data indicate that dectin-1, does not play a vital role in experimental colitis in mice.

Crohn's disease patients have been found to produce antibodies against fungal glycocarbohydrates including $\beta$-glucans and mannans [16,17]. C. albicans is a 

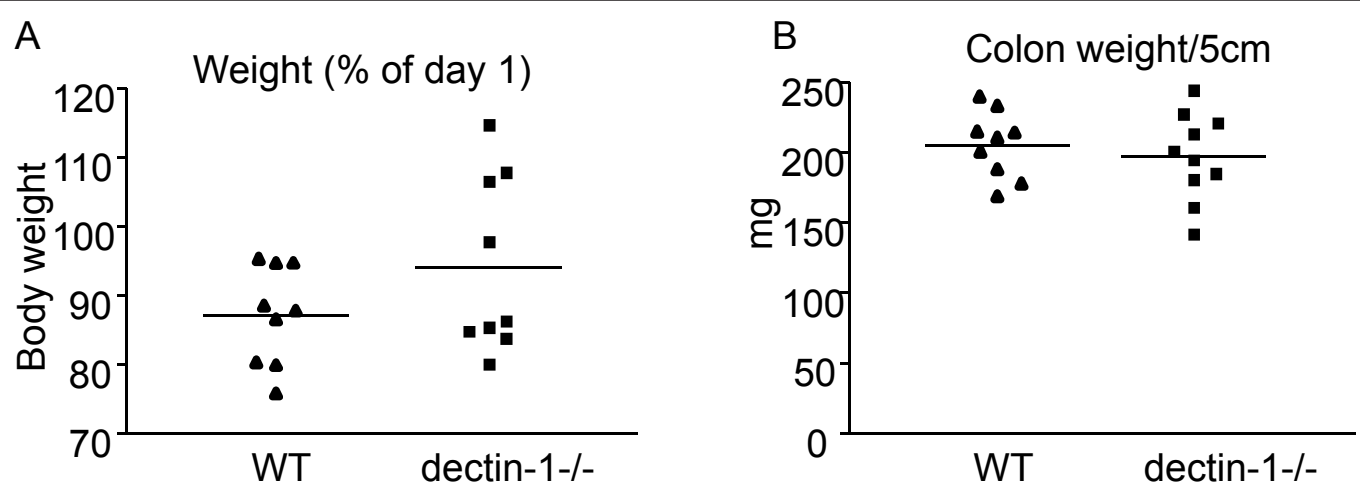
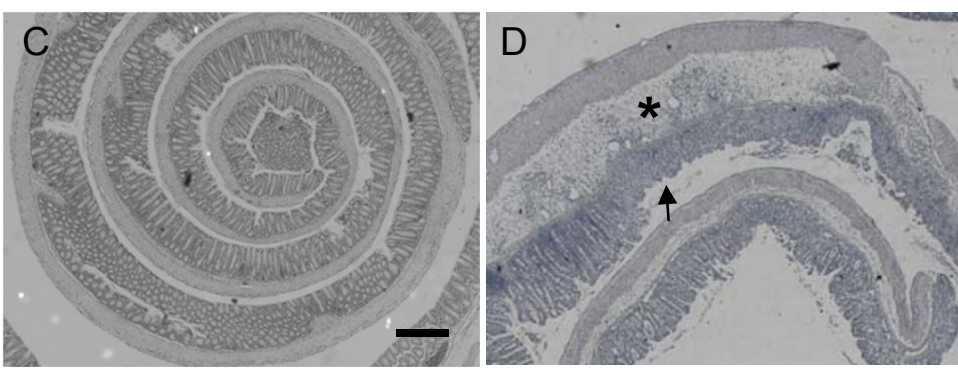

G

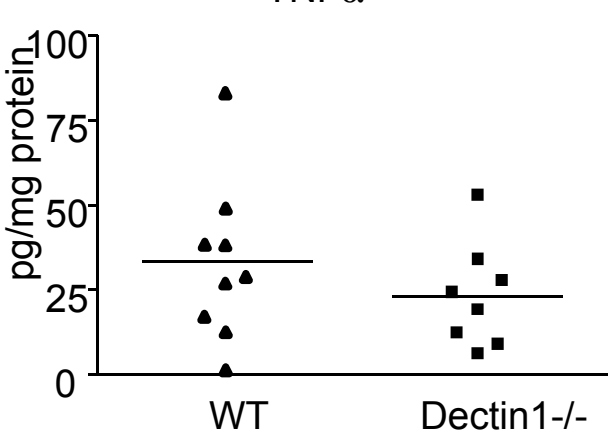

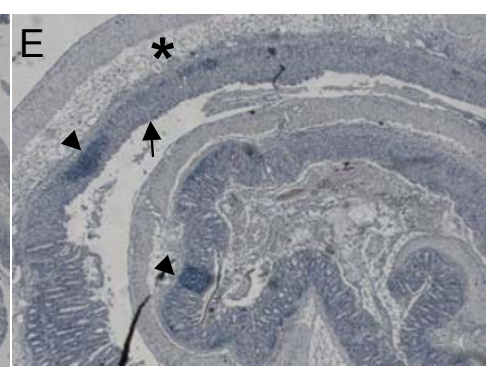

TNF $\alpha$

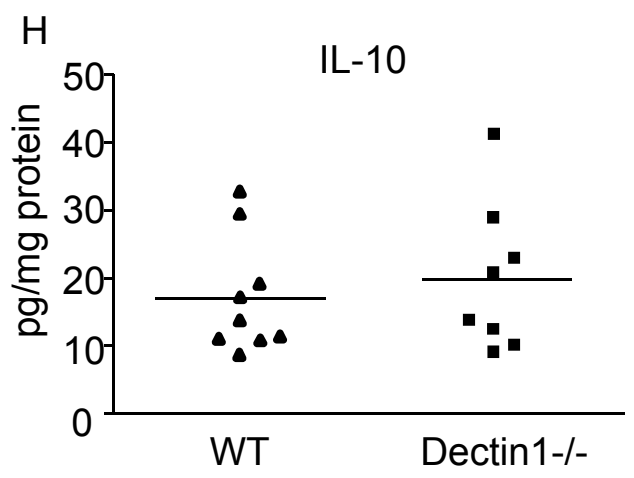

F Total inflammation score colon

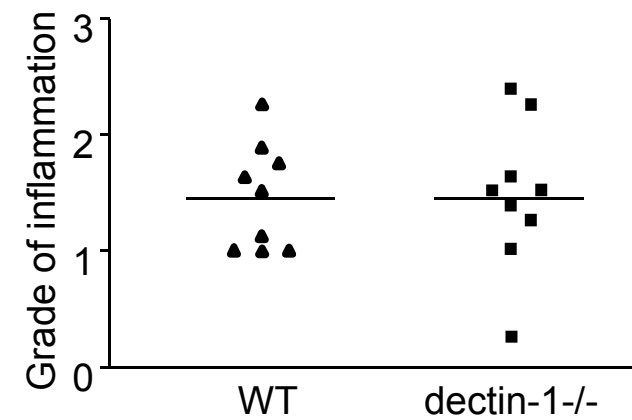

I

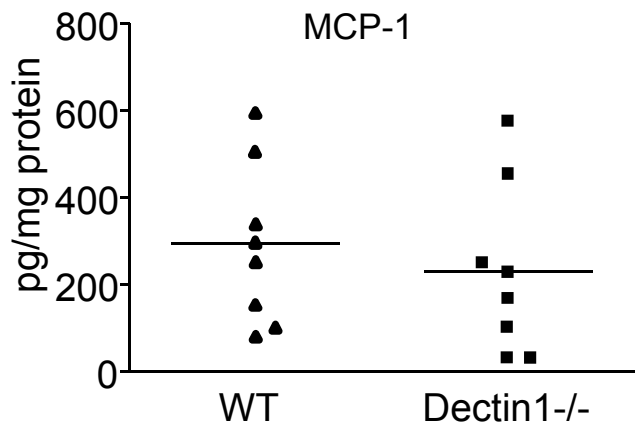

Figure 2 Dectin-1 involvement in DSS induced colitis. Mice were given 1.5\% DSS in their drinking water for 7 days. A) Bodyweights were measured as indication of disease severity in this model, weights are shown as percentage of weight on day seven compared to day one. B) Colons were weighed as an indication of inflammation, shown as weight per $5 \mathrm{~cm}$ colon. F) Longitudinally divided colons were rolled, fixed and embedded in paraffin for routine histology. Colons were evaluated by an experienced pathologist and graded from 0 to 4 points as indicated in table 1. The total inflammation score was determined by the average score of the following criteria: area involved, the number of follicle aggregates, oedema, fibrosis, hyperplasia, erosion/ulceration, crypt loss and infiltration of granulocytes and mononuclear cells. C) Representative picture of healthy colon. D) Representative picture of WT colon after 7 days of DSS induced inflammation. E) Representative picture of dectin1-/- colon after 7 days of DSS induced inflammation. In inflamed colon a large amount of cell infiltration was found in both the mucosa and submucosa (asterisk), areas of cryptloss were clear (arrow) and we also found gut associated lymphoid tissue (arrowheads). Bar, 200 um. G) TNF $\alpha$ protein concentrations in colon lysates $\mathbf{H}$ ) IL-10 protein concentrations in colon lysates I) MCP-1 protein concentrations in colon lysates. The sample means are indicated with a line. A t-test was used for statistical analysis. *, $\mathrm{p}<0.05, \mathrm{n}=10$. 


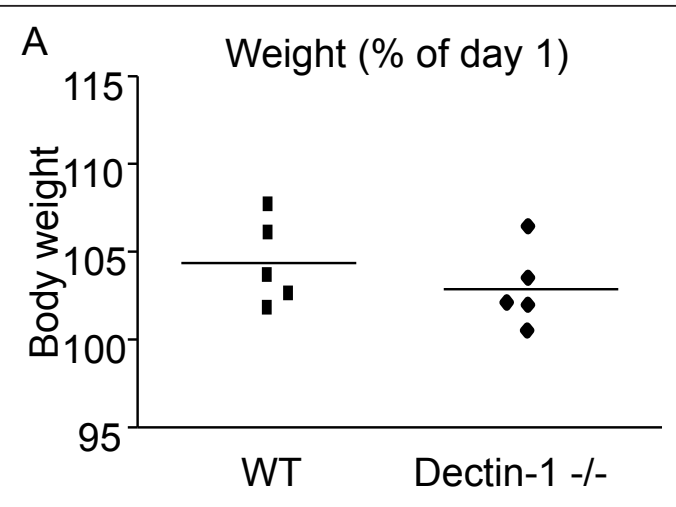

C

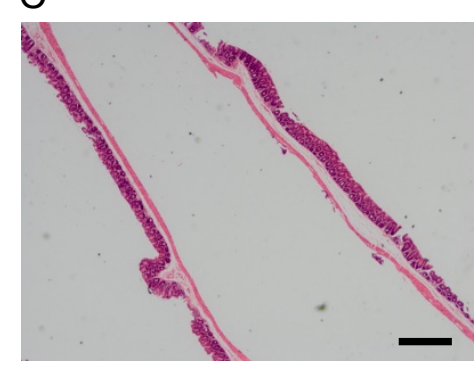

\section{D}

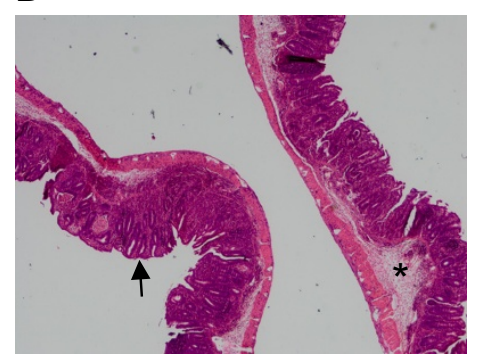

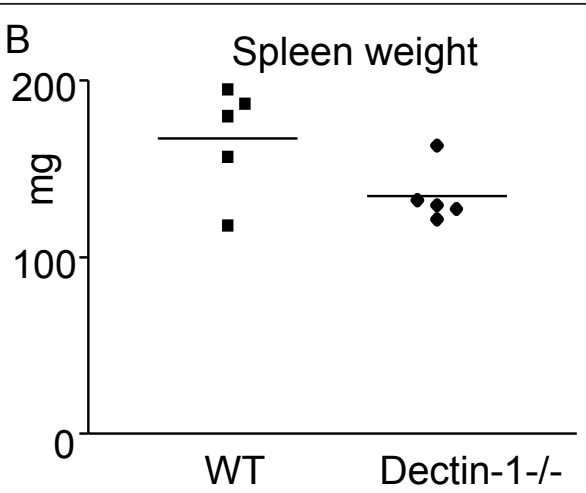

$\mathrm{E}$

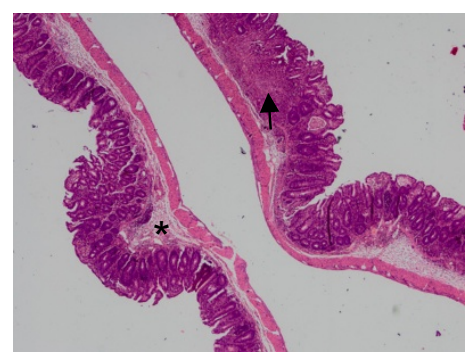

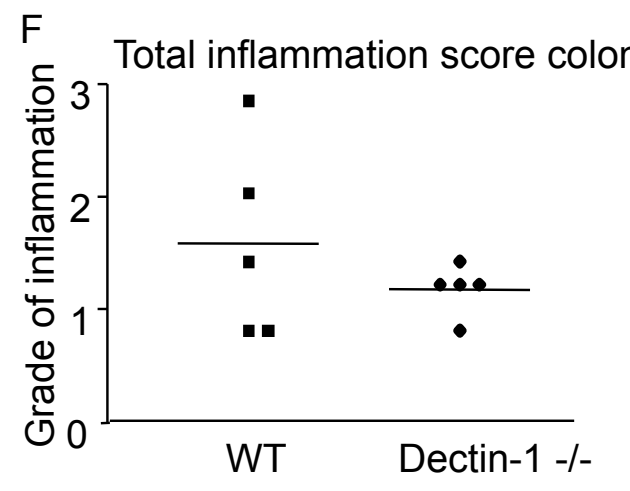
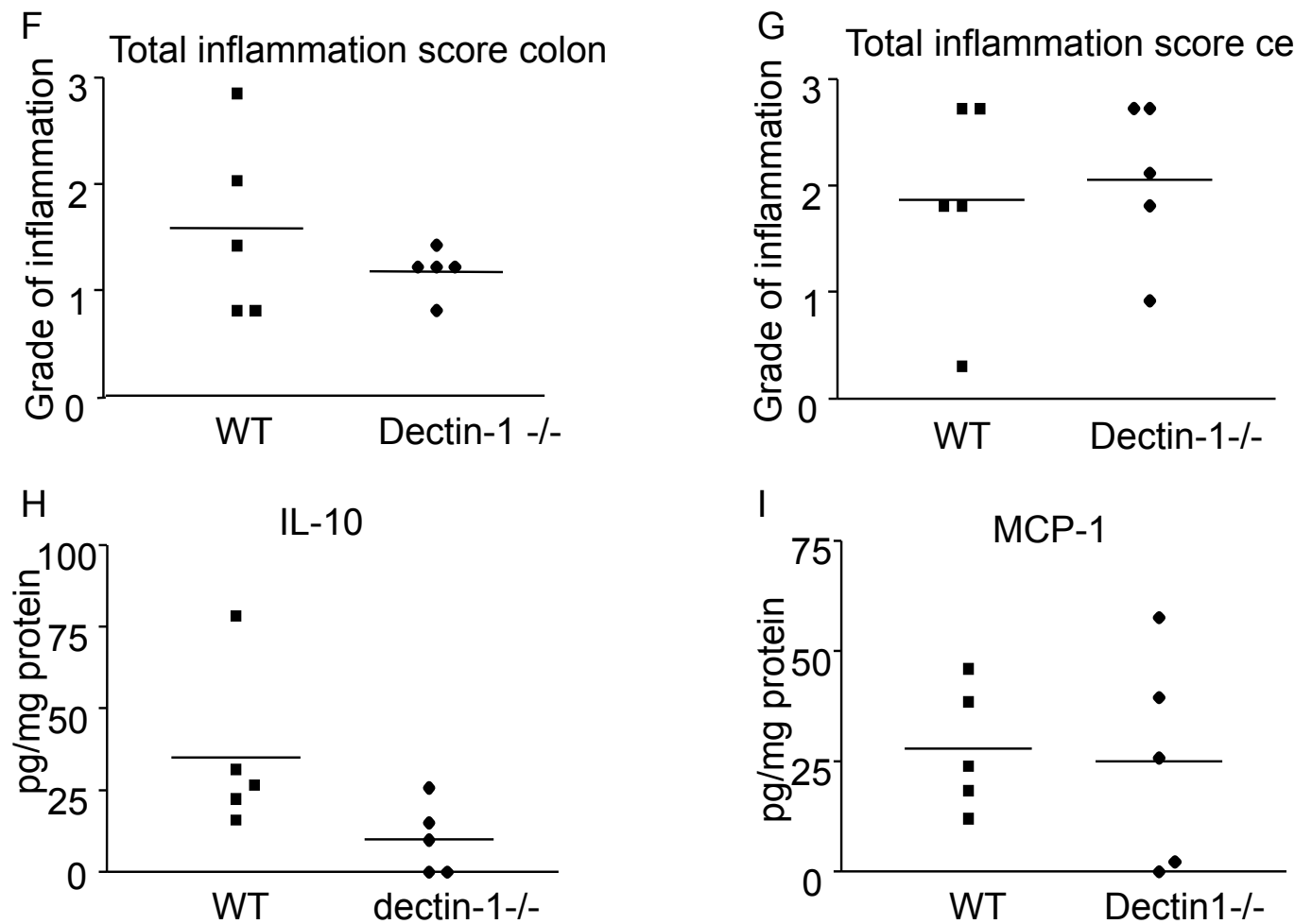

Figure 3 Dectin-1 involvement in $\mathbf{H}$. hepaticus induced colitis. Mice were inoculated intragastrically with $H$. hepaticus and received weekly i. p. injections of $1 \mathrm{mg}$ anti-IL-10R for the duration of four weeks. A) Bodyweights were measured, weights are shown as percentage of weight on day 28 compared to day one. Disease severity was measured using B) spleen weight F) colon total inflammation score and G) cecum total inflammation score. C) Representative picture of healthy cecum. D) Representative picture of WT cecum after H. hepaticus induced colitis. E) Representative picture of dectin-1-/- cecum after H. hepaticus induced colitis. In inflamed cecum a large amount of cell infiltration was found in both the mucosa (arrow) and submucosa (asterisk). Bar, 500 um. H) IL-10 protein concentrations in colon lysates I) MCP-1 protein concentrations in colon lysates. The sample means are indicated with a line. A $t$-test was used for statistical analysis. ${ }^{*}, \mathrm{p}<0.05, \mathrm{n}=5$. 
suspected immunogen for these antibodies [41,42] and as a major receptor for $C$. albicans $[29,43]$, dectin- 1 is likely to be important in immune responses involving patients with an intestinal C. albicans infection. Indeed, C. albicans has been described to aggravate inflammation in DSS induced colitis [44]. However, mice are not naturally infected with $C$. albicans and we did not find Candida species in our mice. We found a fungus of the Rhodutorula spp in the stools of our mice. Besides their possible presence in faeces, these fungi are often found in humid environments like bathrooms and soil and are not considered to be pathogenic or play a role in colitis [33].

We used two different colitis models to determine if dectin-1 plays a role in the progression of intestinal inflammation. When adding DSS to the drinking water for 7 days, mice develop an acute inflammation which is mainly driven by the innate immune system as $\mathrm{T}$ and $\mathrm{B}$ cell deficient mice like RAG-/- and SCID animals also develop colitis after feeding DSS [35,45]. The second model we used was based on infection with $H$. hepaticus in mice that received antibodies directed at the IL-10 receptor. In these mice inflammation develops over a course of four weeks and both innate and adaptive immune responses are involved in this chronic model of colitis [28]. In both models, dectin-1 deficient mice did not show any substantial or consistent differences in weight, colon inflammation, systemic inflammation and cytokine responses suggesting that the course of inflammation is the same for WT and dectin-1-/- mice in these models. This was surprising since in-vitro experiments showed that dectin-1 deficiency had significant effects on cytokine responses towards the mouse faeces (Figure 1). It may be that during intestinal inflammation other PRRs compensate for the lack of dectin-1; several other receptors are known to recognise fungi including TLRs [46,47], mannose receptor [29,48], dectin-2 [49] and DC-SIGN [50] and its mouse homologue SIGN-R1 [51]. Since bacteria are the dominant bowel inhabitants and only about $1 \%$ of the intestinal microbiome consists of fungi [14], it may also be possible that dectin-1 involvement in intestinal inflammation is overwhelmed by responses towards the bacterial component.

Various PRR have been shown to play an important role in human IBD and dectin-1 has been shown to co-signal with TLR2 and TLR6 for the production of various pro-inflammatory cytokines $[19,20,22]$. Clearly, although our data suggest dectin-1 signalling is redundant in intestinal inflammation TLR2 and/or TLR6 deficiency does affect experimental colitis via separate mechanisms indicating that dectin-1 deficiency does not seem to affect TLR signalling. This was also indicated by our observation of normal responses to TLR ligands other that dectin-1 in deficient cells. Indeed, a mutation found in human dectin-1 which leads to partial dectin-1 deletion has been shown not to be involved in IBD [26]. It is likely that dectin-1 becomes more relevant when the fungal burden in the intestine increases, for instance due to antibiotic treatment or infection.

\section{Conclusions}

Our in-vitro data suggest that dectin-1 is able to induce a cytokine response towards mouse faeces, however dectin-1 deficiency in mice does not affect the course of inflammation in two models of experimentally induced colitis suggesting that dectin-1 signalling is redundant in experimental colonic inflammation induced by either DSS or H. hepaticus in mice.

\section{Abbreviations}

CLR: C-type lectin-like receptors; DSS: Dextran Sulphate Sodium; IBD: Inflammatory bowel diseases; LPS: Lipopolysaccharide; LTA: Lipoteichoic acid; PRR: Pattern recognition receptor; TLRs: Toll-like receptors; WT: Wild type.

\section{Acknowledgements}

We would like to thank the staff of our animal facility and Suzanne Duijst for care of the animals used in this study, Francisca Hilbers for help with the ELISA experiments and Dr. Brenda Olivier for help with

immunohistochemistry. Thanks also to Dr. Gordon D. Brown for the dectin1-/- mice, and Dr. Kevin Maloy for advice with the Helicobacter hepaticus colitis model. Thanks to Dr. R.M. van den Wijngaard for helpful discussion. WJ is supported by a grant from the Netherlands Organization for Scientific Research (NWO-VIDI), and Toplnstitute Pharma (T1-215). Publication cost where funded by NWO.

\section{Author details}

Tytgat Institute for Liver and Intestinal Research, Academic Medical Center, University of Amsterdam, AMC, Amsterdam, The Netherlands. '2Department of Medical Microbiology, Academic Medical Center, University of Amsterdam, AMC, Amsterdam, The Netherlands. ${ }^{3}$ Department of Pathology, Academic Medical Center, University of Amsterdam, AMC, Amsterdam, The Netherlands. ${ }^{4}$ Sir William Dunn School of Pathology, University of Oxford, Oxford, UK. ${ }^{5}$ Tytgat Institute for Liver and Intestinal Research, Academic Medical Center, Meibergdreef 69-71, 1105, BK Amsterdam, The Netherlands.

\section{Authors' contributions}

SH participated in the design of the study, experimental work and drafting the manuscript. AO participated in the helicobacter experiments. JR participated in the immunohistochemistry analysis and did the pathology scoring. SD and AV participated in DSS colitis experiments. SG and WJ participated in the design of the study and drafting the manuscript. All authors read and approved the final manuscript.

\section{Competing interests}

The authors declare that they have no competing interests.

Received: 19 October 2011 Accepted: 16 April 2012

Published: 16 April 2012

\section{References}

1. Cario E: Toll-like receptors in inflammatory bowel diseases: a decade later. Inflamm Bowel Dis 2010, 16:1583-1597.

2. Werts C, Rubino S, Ling A, Girardin SE, Philpott DJ: Nod-like receptors in intestinal homeostasis, inflammation, and cancer. J Leukoc Biol 2011, 90:471-482

3. Vijay-Kumar M, Sanders CJ, Taylor RT, Kumar A, Aitken JD, Sitaraman SV, et al: Deletion of TLR5 results in spontaneous colitis in mice. J Clin Invest 2007, 117:3909-3921. 
4. Fukata M, Michelsen KS, Eri R, Thomas LS, Hu B, Lukasek K, et al: Toll-like receptor-4 is required for intestinal response to epithelial injury and limiting bacterial translocation in a murine model of acute colitis. Am J Physiol Gastrointest Liver Physiol 2005, 288:G1055-G1065.

5. Araki A, Kanai T, Ishikura T, Makita S, Uraushihara K, liyama R, et al: MyD88deficient mice develop severe intestinal inflammation in dextran sodium sulfate colitis. J Gastroenterol 2005, 40:16-23.

6. Lowe EL, Crother TR, Rabizadeh S, Hu B, Wang H, Chen S, et al: Toll-like receptor 2 signaling protects mice from tumor development in a mouse model of colitis-induced cancer. PLoS One 2010, 5:e13027.

7. Watanabe T, Asano N, Murray PJ, Ozato K, Tailor P, Fuss IJ, et al: Muramyl dipeptide activation of nucleotide-binding oligomerization domain 2 protects mice from experimental colitis. J Clin Invest 2008, 118:545-559.

8. Zaki MH, Boyd KL, Vogel P, Kastan MB, Lamkanfi M, Kanneganti TD: The NLRP3 inflammasome protects against loss of epithelial integrity and mortality during experimental colitis. Immunity 2010, 32:379-391.

9. Rakoff-Nahoum S, Hao L, Medzhitov R: Role of toll-like receptors in spontaneous commensal-dependent colitis. Immunity 2006, 25:319-329.

10. Franchimont D, Vermeire S, El HH, Pierik M, Van SK, Gustot T, et al: Deficient host-bacteria interactions in inflammatory bowel disease? The toll-like receptor (TLR)-4 Asp299gly polymorphism is associated with Crohn's disease and ulcerative colitis. Gut 2004, 53:987-992.

11. Hugot JP, Chamaillard M, Zouali H, Lesage S, Cezard JP, Belaiche J, et al: Association of NOD2 leucine-rich repeat variants with susceptibility to Crohn's disease. Nature 2001, 411:599-603.

12. Ogura $Y$, Bonen DK, Inohara N, Nicolae DL, Chen FF, Ramos R, et al: A frameshift mutation in NOD2 associated with susceptibility to Crohn's disease. Nature 2001, 411:603-606.

13. Villani AC, Lemire M, Fortin G, Louis E, Silverberg MS, Collette C, et al: Common variants in the NLRP3 region contribute to Crohn's disease susceptibility. Nat Genet 2009, 41:71-76.

14. Simon GL, Gorbach SL: Intestinal flora in health and disease. Gastroenterology 1984, 86:174-193

15. Osorio F, Reis e Sousa C: Myeloid C-type lectin receptors in pathogen recognition and host defense. Immunity 2011, 34:651-664.

16. Walker $L$, Aldhous MC, Drummond HE, Smith BR, Nimmo ER, Arnott ID, et al: Anti-Saccharomyces cerevisiae antibodies (ASCA) in Crohn's disease are associated with disease severity but not NOD2/CARD15 mutations. Clin Exp Immunol 2004, 135:490-496.

17. Dotan I, Fishman S, Dgani Y, Schwartz M, Karban A, Lerner A, et al: Antibodies against laminaribioside and chitobioside are novel serologic markers in Crohn's disease. Gastroenterology 2006, 131:366-378.

18. Rothfuchs AG, Bafica A, Feng CG, Egen JG, Williams DL, Brown GD, et al: Dectin-1 interaction with Mycobacterium tuberculosis leads to enhanced IL-12p40 production by splenic dendritic cells. J Immunol 2007, 179:3463-3471.

19. Brown GD, Herre J, Williams DL, Willment JA, Marshall AS, Gordon S: Dectin-1 mediates the biological effects of beta-glucans. J Exp Med 2003, 197:1119-1124.

20. Rogers NC, Slack EC, Edwards AD, Nolte MA, Schulz O, Schweighoffer E, et al: Syk-dependent cytokine induction by Dectin-1 reveals a novel pattern recognition pathway for $\mathrm{C}$ type lectins. Immunity 2005, 22:507-517.

21. Herre J, Marshall AS, Caron E, Edwards AD, Williams DL, Schweighoffer E, et al: Dectin-1 uses novel mechanisms for yeast phagocytosis in macrophages. Blood 2004, 104:4038-4045.

22. Gantner BN, Simmons RM, Canavera SJ, Akira S, Underhill DM: Collaborative induction of inflammatory responses by dectin-1 and Toll-like receptor 2. J Exp Med 2003, 197:1107-1117.

23. LeibundGut-Landmann S, Gross O, Robinson MJ, Osorio F, Slack EC, Tsoni SV, et al: Syk- and CARD9-dependent coupling of innate immunity to the induction of $\mathrm{T}$ helper cells that produce interleukin 17. Nat Immunol 2007, 8:630-638.

24. Osorio F, LeibundGut-Landmann S, Lochner M, Lahl K, Sparwasser T, Eberl G, et al: DC activated via dectin-1 convert Treg into IL-17 producers. Eur J Immunol 2008, 38:3274-3281.

25. Reid DM, Montoya M, Taylor PR, Borrow P, Gordon S, Brown GD, et al: Expression of the \{beta\}-glucan receptor, Dectin-1, on murine leukocytes in situ correlates with its function in pathogen recognition and reveals potential roles in leukocyte interactions. J Leukoc Biol 2004, 76:86-94.
26. de Vries HS, Plantinga TS, van Krieken JH, Stienstra R, van Bodegraven AA Festen EA, et al: Genetic association analysis of the functional c.714 T > $\mathrm{G}$ polymorphism and mucosal expression of dectin-1 in inflammatory bowel disease. PLoS One 2009, 4:e7818.

27. Kullberg MC, Jankovic D, Feng CG, Hue S, Gorelick PL, McKenzie BS, et al: IL-23 plays a key role in Helicobacter hepaticus-induced T celldependent colitis. J Exp Med 2006, 203:2485-2494.

28. Kullberg MC, Jankovic D, Feng CG, Hue S, Gorelick PL, McKenzie BS, et al: IL-23 plays a key role in Helicobacter hepaticus-induced T celldependent colitis. J Exp Med 2006, 203:2485-2494.

29. Heinsbroek SE, Taylor PR, Martinez FO, Martinez-Pomares L, Brown GD, Gordon S: Stage-specific sampling by pattern recognition receptors during Candida albicans phagocytosis. PLOS Pathog 2008, 4:e1000218.

30. Christensen HR, Frokiaer H, Pestka JJ: Lactobacilli differentially modulate expression of cytokines and maturation surface markers in murine dendritic cells. J Immunol 2002, 168:171-178.

31. Lammers KM, Brigidi P, Vitali B, Gionchetti P, Rizzello F, Caramelli E, et al: Immunomodulatory effects of probiotic bacteria DNA: IL-1 and IL-10 response in human peripheral blood mononuclear cells. FEMS Immunol Med Microbiol 2003, 38:165-172.

32. Khatib R, Riederer KM, Ramanathan J, Baran J Jr: Faecal fungal flora in healthy volunteers and inpatients. Mycoses 2001, 44:151-156.

33. Galan-Sanchez F, Garcia-Martos P, Rodriguez-Ramos C, Marin-Casanova P, Mira-Gutierrez J: Microbiological characteristics and susceptibility patterns of strains of Rhodotorula isolated from clinical samples. Mycopathologia 1999, 145:109-112.

34. Miceli MH, Diaz JA, Lee SA: Emerging opportunistic yeast infections. Lancet Infect Dis 2011, 11:142-151.

35. Wirtz S, Neurath MF: Mouse models of inflammatory bowel disease. Adv Drug Deliv Rev 2007, 59:1073-1083.

36. Fox JG, Ge Z, Whary MT, Erdman SE, Horwitz BH: Helicobacter hepaticus infection in mice: models for understanding lower bowel inflammation and cancer. Mucosal Immunol 2011, 4:22-30

37. Williams AM, Probert CS, Stepankova R, Tlaskalova-Hogenova H, Phillips A, Bland PW: Effects of microflora on the neonatal development of gut mucosal T cells and myeloid cells in the mouse. Immunology 2006, 119:470-478.

38. Morland B, Smievoll Al, Midtvedt T: Comparison of peritoneal macrophages from germfree and conventional mice. Infect Immun 1979, 26:1129-1136.

39. Morland B, Midtvedt T: Phagocytosis, peritoneal influx, and enzyme activities in peritoneal macrophages from germfree, conventional, and ex-germfree mice. Infect Immun 1984, 44:750-752.

40. Drummond RA, Brown GD: The role of Dectin-1 in the host defence against fungal infections. Curr Opin Microbiol 2011, 14:392-399.

41. Standaert-Vitse A, Sendid B, Joossens M, Francois N, Vandewalle-El KP, Branche J, et al: Candida albicans colonization and ASCA in familial Crohn's disease. Am J Gastroenterol 2009, 104:1745-1753.

42. Standaert-Vitse A, Jouault T, Vandewalle P, Mille C, Seddik M, Sendid B, et al: Candida albicans Is an Immunogen for Anti-Saccharomyces cerevisiae Antibody Markers of Crohn's Disease. Gastroenterology 2006, 130:1764-1775.

43. Taylor PR, Tsoni SV, Willment JA, Dennehy KM, Rosas M, Findon H, et al: Dectin-1 is required for beta-glucan recognition and control of fungal infection. Nat Immunol 2007, 8:31-38.

44. Jawhara S, Thuru X, Standaert-Vitse A, Jouault T, Mordon S, Sendid B, et al: Colonization of mice by Candida albicans is promoted by chemically induced colitis and augments inflammatory responses through galectin3. J Infect Dis 2008, 197:972-980.

45. Dieleman LA, Ridwan BU, Tennyson GS, Beagley KW, Bucy RP, Elson CO Dextran sulfate sodium-induced colitis occurs in severe combined immunodeficient mice. Gastroenterology 1994, 107:1643-1652.

46. Wang JE, Warris A, Ellingsen EA, Jorgensen PF, Flo TH, Espevik T, et al: Involvement of CD14 and toll-like receptors in activation of human monocytes by Aspergillus fumigatus hyphae. Infect Immun 2001, 69:2402-2406.

47. Netea MG, Van Der Graaf CA, Vonk AG, Verschueren I, Van der Meer JW, Kullberg BJ: The role of toll-like receptor (TLR) 2 and TLR4 in the host defense against disseminated candidiasis. J Infect Dis 2002, 185:1483-1489. 
48. Ezekowitz RA, Sastry K, Bailly P, Warner A: Molecular characterization of the human macrophage mannose receptor: demonstration of multiple carbohydrate recognition-like domains and phagocytosis of yeasts in Cos-1 cells. J Exp Med 1990, 172:1785-1794.

49. Sato K, Yang XI, Yudate T, Chung JS, Wu J, Luby-Phelps K, et al: Dectin-2 Is a Pattern Recognition Receptor for Fungi That Couples with the Fc Receptor \{gamma\} Chain to Induce Innate Immune Responses. J Biol Chem 2006, 281:38854-38866.

50. Cambi A, Gijzen K, de Vries JM, Torensma R, Joosten B, Adema GJ, et al: The C-type lectin DC-SIGN (CD209) is an antigen-uptake receptor for Candida albicans on dendritic cells. Eur J Immunol 2003, 33:532-538.

51. Taylor PR, Brown GD, Herre J, Williams DL, Willment JA, Gordon S: The Role of SIGNR1 and the \{beta\}-Glucan Receptor (Dectin-1) in the Nonopsonic Recognition of Yeast by Specific Macrophages. J Immunol 2004, 172:1157-1162.

\section{Pre-publication history}

The pre-publication history for this paper can be accessed here: http://www.biomedcentral.com/1471-230X/12/33/prepub

doi:10.1186/1471-230X-12-33

Cite this article as: Heinsbroek et al:: Genetic deletion of dectin-1 does not affect the course of murine experimental colitis. BMC

Gastroenterology 2012 12:33.

\section{Submit your next manuscript to BioMed Central} and take full advantage of:

- Convenient online submission

- Thorough peer review

- No space constraints or color figure charges

- Immediate publication on acceptance

- Inclusion in PubMed, CAS, Scopus and Google Scholar

- Research which is freely available for redistribution

Submit your manuscript at www.biomedcentral.com/submit 